\title{
Role of Magnetic Resonance Imaging in Patients with Knee Trauma
}

\author{
Bhautik Kapadia ${ }^{1}$, Bhumika Suthar $^{2 *}$ \\ ${ }^{1}$ Associate Professor, ${ }^{2}$ Assistant Professor, \\ Department of Radiodiagnosis, Medical College Baroda, Vadodara, Gujarat, India.
}

\begin{abstract}
Background: Magnetic resonance imaging (MRI) has become a valuable diagnostic modality for the evaluation of knee joint. MRI not only depicts osseous lesions, but provides information on the cartilage, menisci, ligaments and soft tissues.

Aims: To identify various traumatic consequences of trauma to knee joint. As well as to describe specific primary and secondary signs on MRI pertaining the specific type of injury and to identify role of MRI in operative management of knee trauma.
\end{abstract}

Materials and Methods: Patients with knee trauma with a clinical suspicion of internal derangement were evaluated by MRI. The Various findings suggestive of internal derangement of the knee joint were identified. The results were analyzed, studied and compared with similar studies of the past.

Results: In our study meniscal injury was the commonest condition accounting for 28 patients (80\%) followed by anterior cruciate Ligament (ACL) injury accounting for 21 patients $(60 \%)$. Non-visualization of ACL was found in 4 patients (19.1\%). Secondary sign associated with $A C L$ tear such as associated bone contusion / edema was found in 11 patients (31.4\%). Hyper intensity in the anterior cruciate ligament was found in 17 cases out of which 12 patients showed hyper intensity near the femoral attachment of ACL (70\%) followed by the mid-substance hyper intensity seen in 4 cases $(23.5 \%)$. Medial meniscal tear was the commonest injury associated with the ACL tears accounted for 10 patients (47.62\%) followed by the lateral meniscal tear noted in 7 patients $(33.33 \%)$. Posterior cruciate Ligaments (PCL), lateral collateral ligament and medial collateral ligament injury associated with ACL tear was found in 2 cases $(9.52 \%), 1$ case $(4.76 \%)$ and 3 cases $(14.2 \%)$ respectively. In present study, out of 28 patients with

\section{INTRODUCTION}

"The body does not suffer as much by the damage to the bones, muscles or joints as by the damage to the ligaments." Such an importance of ligaments in maintaining the integrity, stability and mechanical perfection of the joint has been recognized since the Vedic times. Although assessment of internal derangements of the knee trauma begins with clinical evaluation including careful physical examination, imaging is fundamental to accurate diagnosis of many of these derangements.

Radiographs are often required after acute knee trauma. But internal injuries can't be evaluated with conventional radiography. Ultrasonography is useful in imaging the soft tissues about the knee, muscle injury, bone healing, and foreign bodies. The extensor tendons are particularly well suited for sonographic examination using high frequency $(7.5-20 \mathrm{MHz})$. However, sonographic examination of ligaments is limited by the fact that is virtually impossible to scan them otherwise than obliquely-which result in an artifactual hypo echoic appearance. Sonography has the meniscal tears, medial meniscal injury was more common than lateral meniscal injury seen in 21 patients $(75 \%)$. In 5 patients $(17.85 \%)$, both medial and lateral meniscal injury were found. The grade I tear was the common in lateral meniscus seen in 4 cases $(57.1 \%)$ followed by grade III tear seen in 2 cases $(28.6 \%)$. All PCL tear were associated with bone edema I contusion which is the secondary sign associated with PCL injury.

Conclusion: MRI is an excellent noninvasive modality in imaging of the knee and a noninvasive replacement for arthrography and non-therapeutic arthroscopy. It is useful in conditions where arthroscopy cannot detect peripheral meniscal tears, inferior surface tears without apparent damage to cartilage.

Keywords: Cruciate, Ligaments tear, Meniscus.

*Correspondence to:

Dr. Bhumika Suthar, 12/ C, Gurukrupa society, Opposite Shayog, Refinary Road, Gorwa, Vadodara, Gujarat.

Email: bhums22@yahoo.co.in

Article History:

Received: 29-04-2016, Revised: 06-05-2016, Accepted: 19-05-2016

\begin{tabular}{|l|c|}
\hline \multicolumn{2}{|c|}{ Access this article online } \\
\hline $\begin{array}{l}\text { Website: } \\
\text { www.jmrp.com }\end{array}$ & \\
\hline DOI: & \\
10.21276/ijmrp.2016.2.3.052 & \\
\hline
\end{tabular}

been used in the evaluation of collateral ligaments of the knee and the iliotibial band. Joint effusion is also well seen on ultrasonography. MR images provide excellent contrast and high spatial resolution, and permit diagnosis at an early stage of disease. High magnetic field strength MRI units provide a better signal-to-noise ratio, leading to an increased spatial resolution, which is important for the evaluation of joints, and a decrease in examination time, which diminishes motion artifacts and reduces degradation of the MRI images.

The main indication of MRI is in assessment of meniscal and ligament injuries. However it is useful in demonstrating other knee joint abnormalities involving articular cartilage, bone marrow, synovium, patellofemoral joint and adjacent soft tissue.

\section{MATERIALS AND METHODS}

The study was conducted at Medical College and Shree Sayajirao General Hospital, Baroda. 
Thirty five patients with knee trauma with a clinical suspicion of internal derangement were evaluated by Magnetic Resonance Imaging during the period of two years. No selection bias was exercised in terms of patients' age and sex. Few of the patients were followed up arthroscopic ally and managed accordingly. Various findings suggestive of internal derangement of the knee joint were identified. Management and final diagnosis were also noted. The results were analyzed, studied and compared with similar studies of the past.

The MRI scans were performed using either a superconducting 1.5 T PHILIPS GYROSCAN INTERNA superconducting magnet using standard flexible knee coil for acquisition of the images. Axial, coronal and sagittal scans were performed obtained using multislice multiecho sequences with slice thickness of $4 \mathrm{~mm}$.

\section{OBSERVATION AND ANALYSIS}

The common age group was in 41-50 year which comprised $22.8 \%$ of the series, $20 \%$ of the patients in the range of $11-20$ year. The average age of patients was 39 years. The male patients predominated over female patients seen in $71.43 \%$ of the series. In our study meniscal injury was the commonest condition accounting for 28 patients $(80 \%)$ followed by anterior cruciate ligament $(A C L)$ injury accounting for 21 patients $(60 \%)$. (Table 2$)$
In 21 patients with anterior cruciate ligament tears, hyper intensity in the ligament was seen in 17 patients (80.9\%). Non-visualization of $A$ was found in 4 patients (19.1\%). (Fig 1)

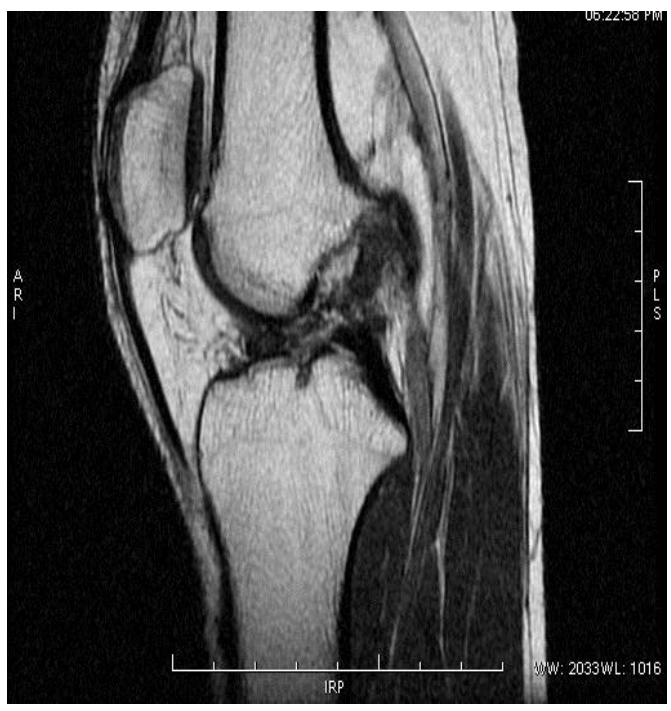

Fig 1: Sagittal STIR Image Showing Heterogenous Signal Intensity in Anterio Cruciate Ligament With Discontinuty of Fibers Complete Tear of ACL

Table 1: Age wise distribution of cases $(n=35)$ :

\begin{tabular}{lcc}
\hline Age group & No. of patients & \% of patients \\
\hline $\mathbf{0 - 1 0}$ & 0 & 00.0 \\
$\mathbf{1 1 - 2 0}$ & 7 & 20.0 \\
$\mathbf{2 1 - 3 0}$ & 6 & 17.2 \\
$\mathbf{3 1 - 4 0}$ & 5 & 14.3 \\
$\mathbf{4 1 - 5 0}$ & 8 & 22.8 \\
$\mathbf{5 1 - 6 0}$ & 5 & 14.3 \\
$\mathbf{6 1 - 7 0}$ & 4 & 11.4 \\
Total & 35 & 100.0 \\
Mean age & & 39 years \\
\hline
\end{tabular}

Table 2: Distribution of cases as per type of injury $(n=35)$

\begin{tabular}{lcc}
\hline Type of injury & No. of cases & \% of cases \\
\hline ACL & 21 & 60 \\
PCL & 03 & 8.5 \\
Meniscus & 28 & 80 \\
Medial Collateral Ligament & 07 & 20 \\
Lateral Collateral ligament & 01 & 2.85 \\
\hline
\end{tabular}

Table 3: Distribution of ACL tears as per signs ( $n=21)$

\begin{tabular}{lcc}
\hline Signs & No. of cases & \% of cases \\
\hline Non visualization & 04 & 19.1 \\
Hyper signal intensity & 17 & 80.9 \\
Associated bone oedema & 11 & 31.4 \\
\hline
\end{tabular}

Table 4: Site of ACL hyperintensity $(n=17)$

\begin{tabular}{lcc}
\hline Site & No. of cases & \% of cases \\
\hline Mid substance & 04 & 23.5 \\
Femoral attachment & 12 & 70.6 \\
Tibial attachment & 01 & 05.9 \\
\hline
\end{tabular}


Bhautik Kapadia \& Bhumika Suthar. MRI in Patients with Knee Trauma

Table 5: Association of other ligamentous injuries with ACL tears $(n=21)$

\begin{tabular}{lcc}
\hline Ligamentous injury & No. of cases & \% of cases \\
\hline Medial Meniscus & 10 & 47.62 \\
Lateral meniscus & 07 & 33.33 \\
Both meniscus & 03 & 14.28 \\
PCL & 02 & 09.52 \\
Lateral collateral ligament & 01 & 04.76 \\
Medial collateral ligament & 03 & 14.20 \\
\hline
\end{tabular}

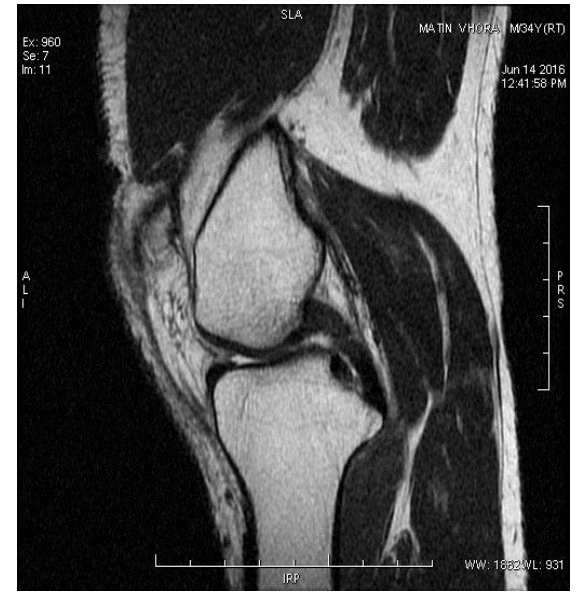

Fig 1: Sagittal FAT SAT MRI Knee Showing High Signal In Medial Meniscus; Grade- 1

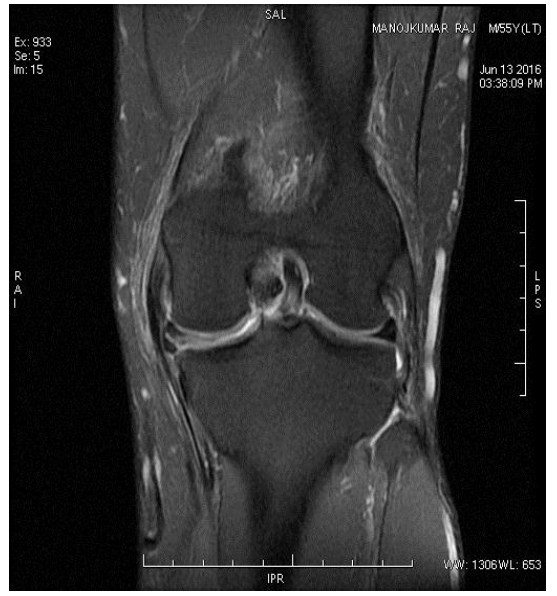

Fig 2: High Signal Intensity Extending to One Articular Surface; Grade 2

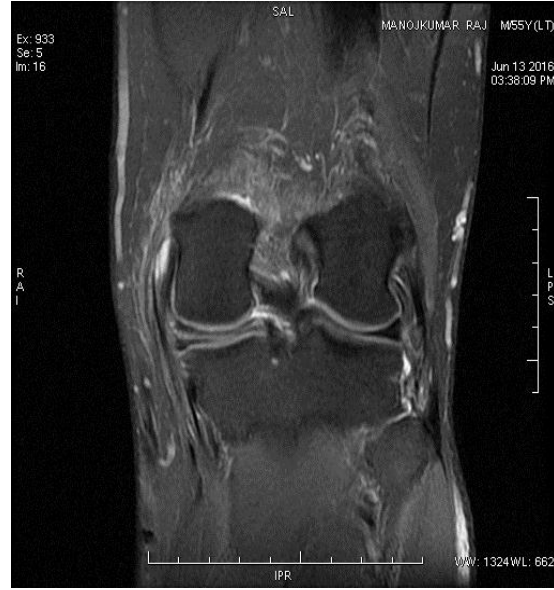

Fig 3: Coronal FAT SAT KNEE MRI Showing High Signal Intensity In Medial Meniscus Extending To Inferior Articular Surface; Grade 3
Secondary sign associated with anterior cruciate ligament tear such as associated bone contusion / edema was found in 11 patients $(31.4 \%)$. In present study hyper intensity in the anterior cruciate ligament was found in 17 cases out of which 12 patients showed hyperintensity near the femoral attachment of ACL $(70 \%)$ followed by the mid-substance hyperintensity seen in 4 cases (23.5\%).(Table 3,4) The medial meniscal tear was the commonest injury associated with ACL tears accounted for 10patients (47.62\%) AND lateral meniscal tear noted in 7 patients $(33.33 \%)$. (Table 5)

In present study, out of 28 patients with the meniscal tears, medial meniscal injury was more common than lateral meniscal injury seen in 21 patients (75\%). (Fig 2)

In 5 patients $(17.85 \%)$, both medial and lateral meniscal injury were found.(Table 6) The grade II tear was the common in medial meniscus seen in 8 cases (38.1\%) followed by grade III tear seen in 7 cases (33.3\%).(Table 7) The grade I tear was the common in lateral meniscus seen in 4 cases $(57.1 \%)$ followed by grade III Tear in 2 cases (28.6\%). (Table 8)

The grade I meniscal injury was common, seen in 10 patients $(35.8 \%)$ followed by grade II and grade III tears in equal instances in patients of meniscal injury. (Table 9)

2 patients of Posterior cruciate ligament tear $(66.6 \%)$ showed discontinuity of the ligament and 1 patient (33.4\%) showed hyper intensity within the ligament.

All cases with Posterior cruciate ligament tear were associated with bone edema / contusion which is the secondary sign associated with PCL injury. (Table 10) (Fig 3)

Table 6: Distribution of Meniscal injury $(n=35)$

\begin{tabular}{lcc}
\hline Meniscal injury & No. of cases & \% of cases \\
\hline Medial Meniscal injury & 21 & 60.00 \\
Lateral Meniscal injury & 07 & 20.00 \\
Both Menisci & 03 & 08.57 \\
\hline
\end{tabular}

Table 7: Grades of injury associated with Medial Meniscus $(n=21)$

\begin{tabular}{ccc}
\hline Grade & No. of cases & \% of cases \\
\hline I & 06 & 28.6 \\
II & 08 & 38.1 \\
III & 07 & 33.3 \\
\hline
\end{tabular}


Table 8: Grades of injury associated with Lateral Meniscus $(n=7)$

\begin{tabular}{ccc}
\hline Grade & No. of cases & \% of cases \\
\hline I & 04 & 57.1 \\
II & 01 & 14.3 \\
III & 02 & 28.6 \\
\hline
\end{tabular}

Table 9: Grades of Meniscal injury $(n=28)$

\begin{tabular}{ccc}
\hline Grade & No. of cases & \% of cases \\
\hline I & 10 & 35.8 \\
II & 09 & 32.1 \\
III & 09 & 32.1 \\
\hline
\end{tabular}

Table 10: Distribution of PCL tears as per signs $(n=3)$

\begin{tabular}{lcc}
\hline Signs & No. of cases & \% of cases \\
\hline Discontinuity & 02 & 66.6 \\
Hyper signal intensity & 01 & 33.4 \\
Associated bone oedema & 03 & 100 \\
\hline
\end{tabular}

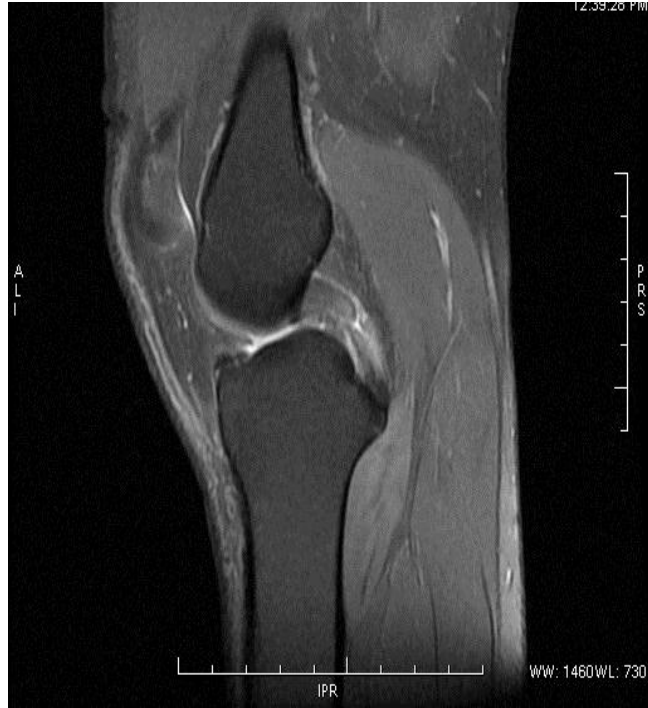

Fig 3: PCL tears; Sagittal FAT SAT MRI KNEE Image Showing High Signal Intensity In Posterio Cruciate Ligament With Intact Fiber Suggesting partial Thickness Tear

\section{DISCUSSION}

Over the past several years, the role of MRI in knee imaging has steadily increased in evaluation of the patients with trauma and is often the main tool for evaluation of suspected internal derangements ${ }^{1}$. Complete evaluation of the capsule, collateral ligaments, menisci and tendons about the knee has been difficult with conventional and CT arthrography. Multiplanar MR images provide significant improvement in assessing these structures.

\section{Anterior cruciate ligament $(A C L)$ Injury}

In our study ACL tear was the condition accounting for 21 patients (60\%). In study of Sonnin et al, ACL injury was noted in $40 \%$ cases. Gentili et al found ACL injury in $60.7 \%$ cases $^{2}$. In present study, hyper intensity in the anterior cruciate ligament was seen in 16 patients (80.9\%) which is concordance with Berquist et al who reported hyper intensity in $A C L$ in $61.9 \%$. Five patients (19.1\%) with $\mathrm{ACL}$ tear showed non-visualization of $\mathrm{ACL}$ which is concordance with the Barry et al (18\%), Shetty et al (14.3\%) and Raochawdhary et al (28.1\%). Secondary signs such as PCL buckling, anterior tibia displacement, uncovered meniscus sign and bone contusions assisted in diagnosis in indeterminate case. In present study, bone contusion / edema are noted associated with ACL tear in 11 patients (31.4\%).

Posterior cruciate ligament (PCL) Injury

PCL tear accounted in 3 cases (8.5\%) and the signs were hyperintensity in 1 patients and discontinuity in 2 patients which is correlated with D S Shetty et al who found PCL tear in $4.34 \%$.

MCL tears are rarely isolated. Usually they are associated with other soft tissue injuries of the knee, such as the anterior cruciate ligament ( $A C L$ ) tears and medial meniscal tears (O'Donahue's triad). ${ }^{3,4}$ Associated medial meniscal tear was seen in 17 patients (47.62\%). which is concordance to the Kai-jow Tsai et al who found meniscal injury associated with ACL tear in $14 \%$ cases. Associated lateral meniscus tear was seen in 7 cases (33.33\%) which are in concordance to the Kai-jow Tsai et al who reported lateral meniscal tear in association with ACL tear in $46 \%$ cases.

\section{Meniscal Injury}

The MM tear was more common $(60 \%)$ than LM tears $(20 \%)$ in our study which corresponded with study by La Prade and colleagues. ${ }^{5}$ In present study, out of 28 patients with meniscal injury, grade I meniscal injury (focal/globular intrasubstance tear) was common, seen in 10 patients (35.8\%) followed by grade II (linear intrasubstance tear) and grade III tears (increased signal intensity extending to articular surface). While in the study of D S Shetty et al, Grade III tear was most common followed by grade II and grade I tear. ${ }^{6}$

Discoid meniscus is a dysplastic meniscus with a broad disc like configuration. These are seen best on sagittal images as appearance of bowtie in more than 2 contiguous slices. In our study there was only one patient $(2.85 \%)$ and it was seen in lateral meniscus. This correlated with reports by Weiner et al who found discoid meniscus in $5.2 \%$ and lateral discoid meniscus was more common than medial one. ${ }^{7}$ According to Mink et al, lateral discoid meniscus seen in 1.5 to $15.5 \%$ and medial discoid meniscus in 0.1 to $0.3 \%$.

Bucket handle tears: MRI features: (Fig 4)

In present study, bucket handle tear was found in two cases $(7.14 \%)$ and in both the cases tear was found involving medial meniscus. Double PCL sign was noted in both the cases and in 
one case fragment in notch sign was seen. In the study of Cruse JV III fragment in notch sign seen more $(66 \%)$ than double PCL sign $(53 \%)$ involving medial meniscal tear. ${ }^{8}$

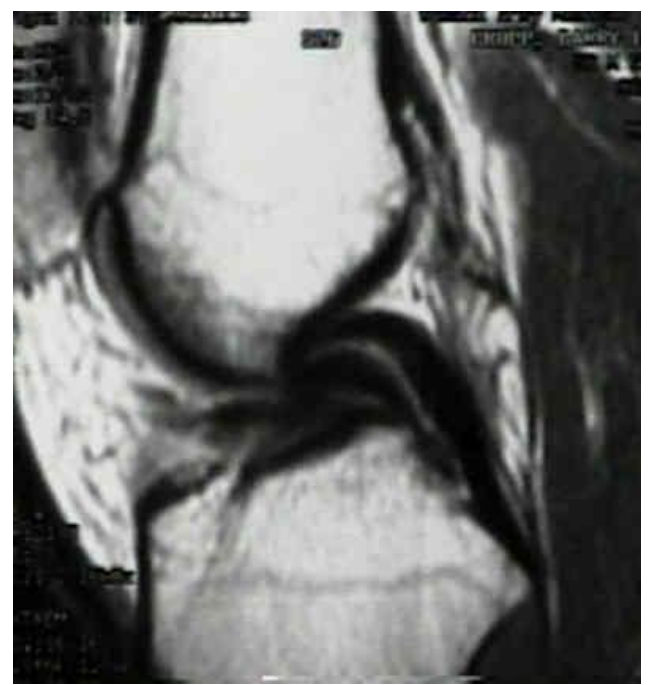

Fig 4: Sagittal PDIMAGE Showing Double PCL Sign Seen In Bucket Handle Tear Of Medial Meniscus.

Collateral Ligament Injury: (Fig 5)

In our study, medial collateral ligament tear was found in 7 cases $(20 \%)$ and lateral collateral ligament tear was found in only one case $(2.85 \%)$. According to $\mathrm{T} \mathrm{H}$ Berquist et al, lateral collateral ligament is injured infrequently compared with the medial collateral ligament.

COLLATERAL LIGAMENT INJURY

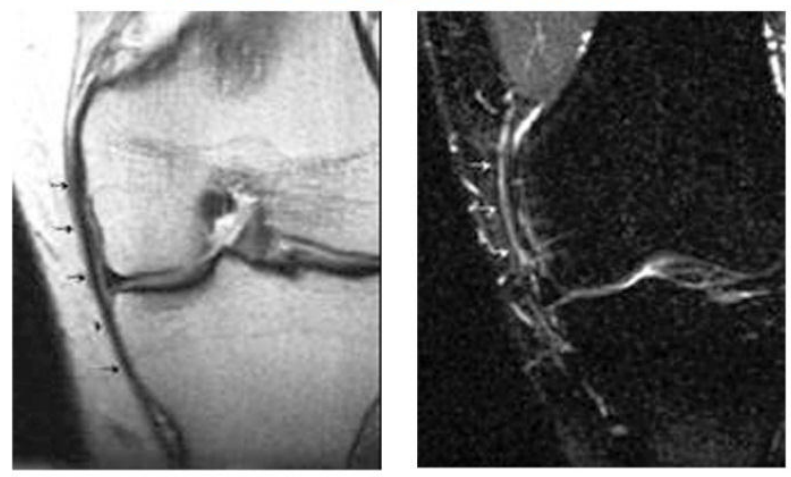

Coronal PD weighted image showing MCL tear with surrounding intermediate signal consistent with edema which appears as hyper SI on FES inversion recovery imge s/o Grade I MCL tear

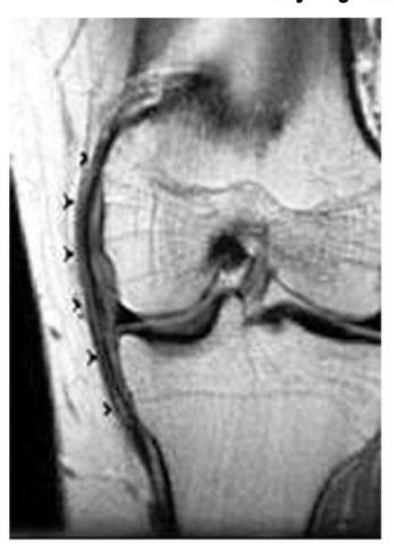

Coronal PD image shows slight thickening of the MCL \& separation from the underlying cortices s/o Grade II MCL tear

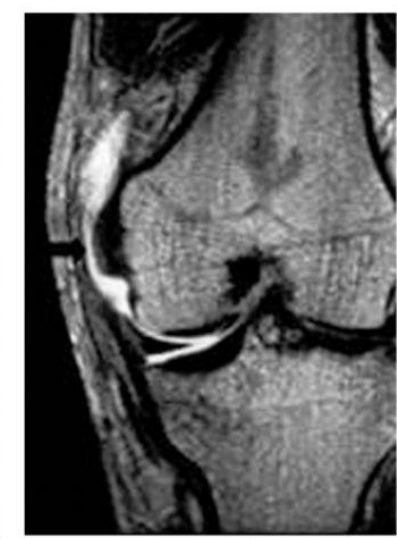

Coronal T2-weighted image showing a disrupted ligament that is thickened $\&$ retractec
with surrounding edema with surrounding edema
s/o Grade III MCL tear

\section{CONCLUSION}

Magnetic resonance imaging is clearly the imaging modality of choice for detecting and exploring joint, osseous and soft tissue injuries to the knee joint. MRI plays a pivotal role in making a precise diagnosis and then guiding treatment decisions. MRI is an excellent noninvasive modality in imaging of the knee and a noninvasive replacement for arthrography and non-therapeutic arthroscopy.

It is useful in conditions where arthroscopy cannot detect peripheral meniscal tears, inferior surface tears without apparent damage to cartilage. Being noninvasive, MR does not involve morbidity associated with arthroscopy and helps in planning the treatment of meniscal and ligament injuries. However, it is the only method for imaging marrow invasion, bone infarcts \& subtle fractures. Many anatomic variants can mimic tears on magnetic resonance imaging.

\section{REFERENCES}

1. Gray SD, Kaplan PA, Dussalt RG. Imaging of knee: current status. Orthopedics Clinics of North America 1997; 28 (4): 643658.

2. Gentili A, Seeger LL, Yao L, et al. Anterior cruciate ligament tear: indirect signs at MR imaging. Radiology 1994; 193: 835-840.

3. Rand JA, Berquist TH. The knee. In: Berquist TH, ed. imaging of Orthopedic trauma, 2nd Ed. New York: Raven Press, 1992; 333-432.

4. Staron RB, Haramati N, Feldman F, et al. O'Donahue's triad: magnetic resonance Imaging evidence. Skeletal Radiol 1994:23: 633-636.

5. Berquist TH. Magnetic resonance techniques in musculoskeletal diseases. Rheurn Clin North Am 1991; 17:599615.

6. Shetty, D.S., Lakshar, V.N. and Krishna, G.K. (2002) Magnetic Resonance Imaging in Pathological Conditions of Knee. Indian Journal of Radiology and Imaging, 12, 375-

7. Weiner B, Rosenberg N. Discoid medial meniscus: association with bone changes in the tibia. J Bone Joint Surg Am. 1974; 56:171-173. [PubMed]

8. Crues JV III. Magnetic resonance imaging of knee menisci. Pre $\urcorner$ sented at the Society Of Magnetic Resonance in Medicine, Amsterdam. The Netherlands. 1989.

\section{Source of Support: Nil. Conflict of Interest: None Declared.}

Copyright: () the author(s) and publisher. IJMRP is an official publication of Ibn Sina Academy of Medieval Medicine \& Sciences, registered in 2001 under Indian Trusts Act, 1882.

This is an open access article distributed under the terms of the Creative Commons Attribution Non-commercial License, which permits unrestricted non-commercial use, distribution, and reproduction in any medium, provided the original work is properly cited.

Cite this article as: Bhautik Kapadia, Bhumika Suthar. Role of Magnetic Resonance Imaging in Patients with Knee Trauma. Int J Med Res Prof. 2016; 2(3):238-42. 